\title{
O livro didático como instrumento mediador no processo de ensino- aprendizagem de língua portuguesa: a produção de textos
}

\author{
The textbook as mediator instrument of \\ learning-teaching process of Portuguese \\ language: texts production
}

Dulce Cassol Tagliani*

Universidade Federal do Rio Grande

Natal - Rio Grande do Norte / Brasil

\begin{abstract}
RESUMO: Tendo como base teórica os estudos sobre os gêneros discursivos e a teoria da atividade, este texto aborda questões relativas ao uso do livro didático (LD) de Língua Portuguesa. Verificamos a relação entre os agentes escolares e esse instrumento, focando as atividades de produção textual escrita, obtidas a partir de aulas observadas em uma escola pública do município de Rio Grande, RS. Observamos o uso desse material sob a ótica do Programa Nacional do Livro Didático e o conhecimento dos professores em relação ao LD. Verificamos ainda em que medida esse uso contribui para a formação da competência discursiva do aluno. Os resultados demonstram divergências quanto ao uso do livro didático como mediador do trabalho com a produção de textos, em função da (re)apresentação e (re)significação dos objetos de ensino que constituem a natureza discursiva do gênero LD de língua portuguesa.
\end{abstract}

PALAVRAS-CHAVE: ensino, língua portuguesa, livro didático, produção textual.

ABSTRACT: Based on theoretical studies of the genres and the theory of activity, this paper addresses issues relating to the use of textbooks in Portuguese. We found the relationship between school agents and this mediation instrument, focusing on production of written activities, obtained from classes in a public high school in Rio Grande, RS. The use made of this material was observed considering the evaluation presented by the National Textbook Program and the teachers' knowledge about the textbook. We also observed how such use contributes to the development of students' discursive competence. The results show that there are differences in the use of textbooks as a mediator of text production, depending mainly on the (re) presentation and (re)signification of the teaching objects that compose the discursive nature of the Portuguese textbook genre.

KEYWORDS: education, Portuguese, textbook, text production.

*dulcetagliani@vetorial.net 


\section{As práticas de linguagem em sala de aula: algumas considerações}

O processo de ensino-aprendizagem de língua portuguesa é objeto de discussão em diferentes níveis, seja pelo Estado, por meio de aparelhos competentes, seja pela academia, entre professores e acadêmicos, e ainda pela escola, onde as práticas pedagógicas realmente se efetivam. Inúmeros estudiosos, de diferentes filiações teóricas, procuram trazer à tona os principais problemas que envolvem tal processo. A falta de objetivos claros de ensino, a indefinição da concepção de linguagem e de gramática subjacente às práticas pedagógicas, critérios inconsistentes de avaliação, evasão e repetência escolar, baixo desempenho dos alunos em habilidades básicas de leitura e produção de textos são apenas alguns exemplos dos inúmeros problemas que afligem a esfera escolar.

Além disso, há um visível descompasso entre a realidade e os conhecimentos dos quais os alunos devem se apropriar. A realidade da maioria dos estudantes brasileiros faz despontar necessidades que extrapolam os limites de um ensino taxionômico mantido por alguns programas escolares. $\mathrm{O}$ objetivo de tornar o aluno competente discursivamente passa, acima de tudo, pela capacidade da escola em propiciar situações de aprendizagem que possam satisfazer tais necessidades.

Com base em pesquisas anteriores desenvolvidas no contexto escolar, na experiência profissional adquirida na área de estágios supervisionados e em projetos voltados para a observação da prática de sala de aula, percebemos que o ensino de língua portuguesa está, em grande parte, vinculado a uma perspectiva gramatical que não envolve a realidade social do aluno em sua prática. As práticas voltam-se, predominantemente, para aspectos formais e estruturais, desconsiderando a natureza funcional e interativa da língua (MARCUSCHI, 2003). As atividades de leitura e escrita, quando realizadas, raramente ultrapassam os limites do ler e interpretar superficialmente o texto, ou do produzir um texto para o professor atribuir uma nota.

As discussões continuam quando o assunto é livro didático de língua portuguesa. A resistência em relação a seu uso persiste, principalmente em função das críticas voltadas para os aspectos basilares das práticas de linguagem: as práticas de leitura, de produção de textos e de análise linguística. A polêmica envolve, principalmente, o uso, ou não, dos livros didáticos que hoje são disponibilizados pelo governo federal às escolas públicas do país, considerando a qualidade desse material. 
A oposição que, de certa maneira, ainda se mantém ao livro didático vem desde a década de 70 e, principalmente, a de 80 , quando o material didático era visto "como uma tecnologia pouco adequada a processos efetivos de aprendizado; como resultado de interesses econômicos envolvidos em sua produção e comercialização; e identificado aos efeitos de controle que exerce sobre a ação docente e sobre o currículo" (BATISTA, 2003, p. 45). A concepção de livro didático (LD) que se tinha, então, é de estruturador das práticas docentes em função da intensa ampliação do sistema de ensino e de processos de recrutamento docente mais amplos e menos seletivos.

Essa concepção ainda persiste e é pouco adequada para responder às exigências apresentadas pelo contexto educacional contemporâneo, "marcado pela afirmação da diversidade e flexibilidade das formas de organização escolar, originadas pela necessidade de atender aos diferentes interesses e expectativas gerados por fatores de ordem cultural, social e regional" (ROJO; BATISTA, 2003, p. 49). Assim, é necessário, segundo os autores, que se amplie essa concepção de LD, também pressuposta pelo Programa Nacional do Livro Didático (PNLD), para que tenhamos um ensino de melhor qualidade e adequado às exigências atuais.

Numa perspectiva sócio-histórica e cultural, o livro didático pode ser considerado como um instrumento que organiza os objetos de ensino considerados necessários para satisfazer as necessidades de ensino-aprendizagem formal da língua portuguesa, em diferentes contextos. Vários interesses entram em conflito, em função das esferas de produção, de avaliação e de circulação, o que envolve, necessariamente, as editoras, os programas oficiais, os professores e os alunos (BUNZEN, 2007).

O uso de livros didáticos é bastante comum nas escolas e, em muitos casos, facilita sobremaneira a vida do professor, assumindo papel central no processo de ensino-aprendizagem. Entretanto, conforme informações contidas no Guia do Livro Didático (BRASIL, 2007, p.19), o trabalho com o material "não pode prescindir do professor", que deve "pensar nos usos diferenciados que um LD pode permitir, como alterações de seqüências, atividades complementares, aspectos diversos da realidade local etc.”. Ainda com relação à presença do livro didático nas escolas, percebemos que ele representa, em muitos casos, a única possibilidade de leitura tanto no ambiente escolar quanto no ambiente familiar do aluno.

Apesar de considerarmos o pressuposto de que o LD é o principal instrumento mediador do processo de ensino-aprendizagem de língua 
portuguesa, verificamos que não há um uso efetivo desse material em sala de aula, no sentido de haver intervenções, por parte do professor, nas práticas de linguagem organizadas via LD. O fato é que ele está na escola pública, e isso nos direciona para o principal objetivo deste estudo, qual seja verificar em que medida o uso do livro didático nas atividades escolares proporciona práticas de produção de textos escritos efetivamente voltadas para o desenvolvimento das necessidades discursivas dos alunos. Pretendemos ainda que este trabalho contribua para a busca de possíveis soluções para os problemas que ainda perpassam o processo de ensino e aprendizagem de língua portuguesa, principalmente se considerarmos as práticas de produção de textos escritos, mediadas ou não pelo livro didático.

Para atingir esses objetivos, buscamos subsídios em observações de sala de aula numa turma de $5^{\mathrm{a}}$ série de uma escola pública de ensino fundamental, do município de Rio Grande, RS. Tais observaçōes estavam voltadas para as práticas de linguagem desenvolvidas pela professora via livro didático. Neste trabalho o foco está, especificamente, nas atividades de produção textual escrita. Contudo, em função de não termos observado, durante o período em que estivemos na escola, nenhuma proposta de produção textual escrita mediada pelo livro didático, optamos por considerar apenas a proposta de produção escrita sem a mediação do LD e, por essa razão, estabelecermos um paralelo entre essa prática e as propostas apresentadas pelo LD, trazendo também para a discussão as orientações dos Parâmetros Curriculares Nacionais (PCN). A coleção de língua portuguesa escolhida nessa escola, por meio do Programa Nacional do Livro Didático (PNLD/2008), foi Tudo é linguagem, das autoras Ana Borgatto, Terezinha Bertin e Vera Marchezi.

\section{As práticas de produção textual em livros didáticos}

Como já referido, o uso do LD nas escolas brasileiras ainda é polêmico, principalmente em função do histórico negativo relacionado a sua qualidade. Por essa razão, por volta de 1990, o MEC demonstra preocupação em relação a esse aspecto e lança diretrizes para a organização desse material. Nesse sentido, estabelece critérios gerais para a avaliação dos materiais que seriam adquiridos, além de requisitos mínimos que um $\mathrm{LD}$ deveria preencher. Tais procedimentos repercutem com maior intensidade apenas em 1996, momento em que se inicia um processo de análise e avaliação sistemático e contínuo.

Nos últimos anos, em função das diversas alterações feitas, há um renovado interesse no $\mathrm{LD}$, o que se deve, principalmente, às avaliaçóes 
periódicas feitas via PNLD, considerando as transformaçóes que ocorreram no contexto educacional brasileiro contemporâneo e as orientações advindas da LDB, dos Parâmetros Curriculares Nacionais e das Diretrizes Curriculares Nacionais.

Esse é um aspecto importante relacionado ao perfil dos LDs, visto que há a indicação, já na capa de alguns desses livros, de que eles estão de acordo com os PCN. Tal referência parece demonstrar a preocupação dos autores em contemplar as indicações feitas pelo referido documento, no sentido de renovar antigas práticas e apresentar um projeto educacional que se volte para o exercício efetivo da cidadania e para a participação plena no mundo letrado.

Dessa forma, é importante que se considere o papel do LD como "instrumento que favoreça a aprendizagem do aluno, no sentido do domínio do conhecimento e no sentido da reflexão na direção do uso dos conhecimentos escolares para ampliar sua compreensão da realidade..." (ROJO; BATISTA, 2003, p. 44). Em função disso, é importante olhar criticamente as práticas de linguagem viabilizadas pelo $\mathrm{LD}$, assim como o uso feito pelo professor, na sala de aula, dessa complexa ferramenta. Por essa razão, voltamos nosso olhar para as práticas de produção de textos apresentadas pelo LD e sua aplicação no contexto escolar.

Uma síntese relacionada a características dos LDs destinados ao ensino fundamental, baseada em Rojo (2003), indica que há aspectos positivos e também negativos com relação ao quesito produção de textos. Assim, destacase como positiva a qualidade dos textos apresentados, no que se refere à composição do material - autênticos; variados quanto à esfera de circulação e gêneros; representativos quanto à autoria; adequados ao aluno. Entretanto, há o predomínio de textos que representam a variedade padrão, língua escrita; não há diversidade de contextos de origem dos textos e tampouco de variedades linguísticas. Especificamente com relação à produção de textos, também os aspectos relacionados à situação de produção, ao plurilinguismo e à heteroglossia são deixados de lado. Não há um trabalho voltado para a diversidade de gêneros e suas variedades de registros linguísticos e pouca reflexão sobre a situação de produção em que a produção de textos dos alunos ocorrerá. O foco continua na língua padrão.

Ainda com relação às características das práticas de produção de textos escritos, via LD, Reinaldo (2005) discute, num primeiro momento, as perspectivas de tratamento dessa produção. Segundo ele, ao pensarmos na produção como produto, estaremos seguindo pressupostos da Linguística de 
Texto (década de 80), que apresenta em seus pressupostos a percepção de que o texto não deve ser considerado apenas pela sua estrutura, mas também pela construção dos seus sentidos, objetivando ampliar esse domínio do ensino da língua. Assim, é importante considerar a leitura e a escrita como movimentos complementares no desenvolvimento da competência textual do aprendiz, pois é por meio da leitura que o aluno perceberá traços específicos de um texto, o que o levará à construção adequada e eficiente de seus textos.

Ainda sob essa perspectiva, devemos perceber que a descrição do funcionamento da língua extrapola o nível da frase - a competência textual não equivale à competência frásica. Isso seria uma base teórica insuficiente para abarcar o funcionamento do texto.

A exploração da tipologia textual, na década de 90 , considerada uma estrutura relativamente autônoma, com organização interna própria, ainda persiste como forma básica de referência ao ensino da escrita. Nesse sentido, ao considerarmos a noção de gêneros como um conjunto de enunciados de uso concreto na sociedade, a narração, a descrição e a dissertação, tipologias de base clássica, passariam a ser consideradas formas de composição dos diversos gêneros de circulação social (REINALDO, 2005).

Nessa perspectiva, o texto "é entendido como produto empírico de uma ação verbal, ou seja, uma unidade lingüística que se caracteriza por uma organização de elementos, segundo regras coesivas que garantem a transmissão de um conteúdo de forma coerente" (Id., p.92).

$\mathrm{Na}$ perspectiva do texto como processo, há dois fatores que atuam paralelamente ao ato de escrever textos: fatores sociais (práticas da realidade social que cerca o indivíduo) e fatores cognitivos (conhecimento de mundo, da língua e do tipo de texto). Essa abordagem tem como pressuposto a necessidade de se criar situações favoráveis ao desenvolvimento de potencialidades cognitivas, além da compreensão de que o ato de escrever se constitui num processo de monitoração que envolve etapas de revisão do texto produzido.

É importante considerar, conforme Reinaldo (2005), que os pressupostos sociocognitivistas não são suficientes para explicar de forma adequada o processo de produção de textos. Nesse sentido, o paradigma sociointeracionista, centrado na noção de linguagem como interlocução, volta-se para um processo de produção orientado "pela idéia de que a apropriação da linguagem e das práticas sociais se dá a partir de um percurso do social para o individual, sempre mediado pelo signo e pelo outro" (Id., p. 95). Isso significa dizer que o aprendiz deverá ter condiçóes de apropriar-se de habilidades de estruturação do texto, sendo capaz de se deslocar do papel de autor para o papel de leitor. 
O reflexo dessas concepções do trabalho com a produção de textos nos LDs, como apontado na literatura sobre o assunto, nos remete para livros cujos autores demonstram preocupação em favorecer a realização do trabalho, no sentido de possibilitar ao aluno a leitura de diversos gêneros sobre um mesmo tema, além de dar orientações no sentido de organização prévia do texto e revisão individual do texto produzido. Por outro lado, a sensibilidade demonstrada em incluir textos representativos de diversos gêneros para leitura não necessariamente vem acompanhada de orientaçôes metodológicas adequadas e suficientes para a produção desses textos - normalmente são instruçōes de caráter superficial (REINALDO, 2005).

A partir disso, o referido autor resume as principais tendências metodológicas da orientação para produção de textos escritos em manuais didáticos: adoção da tipologia de base clássica como referência principal para a progressão no domínio da escrita; a não distinção teórica entre sequência textual e gênero de texto; a ausência na denominação do tipo de texto a ser produzido (ou denominação inusitada); apelo demasiado à criatividade traduzida na preferência pelo texto literário como objeto de produção; e, por fim, ausência de critérios de avaliação que orientem a participação do outro na construção do texto (como seria necessário para uma revisão colaborativa, por exemplo, em que a participação do outro é fundamental).

Em função de termos referenciais curriculares nacionais orientando as práticas de linguagem em sala de aula, achamos por bem discutir neste trabalho as indicações feitas pelos $\mathrm{PCN}$ em relação às práticas de produção de textos. Assim, considerando neste momento apenas a produção de textos escritos, verificamos que há indicações no sentido de que sejam realizadas atividades de transcrição de textos, objetivando focar o registro do texto original e o domínio das convenções gráficas da escrita; atividades de reproduções, paráfrases e resumos, que permitiriam tratar de aspectos coesivos da língua, de aspectos do plano da expressão, do como dizer; atividades de decalque, em que os aspectos formais dos gêneros já estariam definidos - o foco estaria no plano de expressão, no como dizer; atividades de produção que envolvam autoria ou criação, momento em que a tarefa do aluno se torna mais complexa em função da necessidade de articular plano de expressão (como dizer) e plano de conteúdo (o que dizer); atividades de refacção de textos, o que permitiria ao aluno um distanciamento de seu texto, de forma que possa atuar criticamente sobre ele. Além disso, permitiria ao professor a organização de atividades voltadas para a instrumentalização linguística do aluno, no sentido de revisar seu texto (BRASIL, 1998, p. 76). 
Considerando todos esses aspectos, discutimos, na seção seguinte, as práticas de produção de textos em aulas observadas numa turma de $5^{\mathrm{a}}$ série de uma escola pública de ensino fundamental do município de Rio Grande, RS.

\section{Produção textual: teoria X prática}

Durante o desenvolvimento deste trabalho, observamos um total de 20h/a, das quais em apenas 3h/a foram realizadas práticas de produção de textos, escritos e orais. Foram realizadas quatro sequências de atividades de produção de textos, mas apenas uma contemplou a produção de texto escrito. As três sequências de atividades orais desenvolvidas foram mediadas pelo LD. A única produção escrita não teve a mediação do $\mathrm{LD}$, mas foi significativa para a nossa análise, já que vai de encontro às principais orientações previstas nos referenciais curriculares nacionais e também às indicaçôes de práticas de linguagem que favoreçam o desenvolvimento e/ou ampliação da competência discursiva do aluno, conforme discussões oriundas da academia.

Apresentamos, então, a única atividade de produção de texto escrito realizada durante nossas observaçôes. Nesta aula, temos a seguinte dinâmica:

- solicitação de um texto dissertativo, sem referência ao gênero;

- definição do tema: dia das mães;

- apresentação de um roteiro para servir de apoio aos alunos (uso livre), com as seguintes questôes:

1. O que deixa minha mãe feliz?

2. O que a deixa irritada comigo? O que faço para acalmá-la?

3. Qual seu lazer, seu divertimento? O que faz nas horas vagas?

4. Qual seu estilo musical?

5. Como gosta de se vestir?

6. O que pretendo fazer no domingo dedicado às mães?

Após a apresentação do roteiro, a professora faz várias observações sobre a atividade, enfatizando que os alunos podem escrever sobre as preferências da mãe, as ocasiōes em que a mãe se aborrece e suas atitudes. Além disso, propõe, como ponto de partida, a seguinte questão, colocada oralmente: "O filho chega em casa com uma nota ruim; qual a atitude de sua mãe e sua atitude também?". O texto foi produzido em aula e entregue à professora nesse dia. Nas aulas seguintes, não houve nenhuma referência a esse trabalho e o texto não foi devolvido aos alunos. Podemos perceber, nessa sequência, que o 
trabalho foi centralizado na tipologia, sem nenhum tipo de interação e com fins puramente avaliativos.

Como descrito anteriormente, a atividade não indica o gênero a ser produzido cita apenas a tipologia, no caso texto dissertativo. Em função da não indicação do gênero, outras variáveis também são, automaticamente, desconsideradas, visto que o trabalho envolvendo gêneros traz consigo o pressuposto de uma atividade que faça referência aos objetivos da proposta, indicação do destinatário e, consequentemente, da variedade linguística, do contexto de circulação, visto que a socialização do texto é uma necessidade da proposta, entre outros elementos.

Há que se considerar ainda que essa prática escolar voltada para a produção de um "texto dissertativo" envolve outras concepções, como a da Linguística Textual da década de 1980, por exemplo, cujo foco está no princípio organizador do texto, e assim distingue a tipologia textual usada recorrentemente em livros didáticos e aulas de produção de textos: tipo narrativo, tipo expositivo, tipo argumentativo (ou argumentativo-dissertativo, ou dissertativo), tipo injuntivo e tipo preditivo (KOCH; FÁVERO, 1987). Ou também como afirma Bunzen (2007), a consideração de que o foco no texto dissertativo-argumentativo estaria relacionada a um objeto que remonta ao ensino da Retórica Clássica e os elementos de produção que o constitui (inventio, dispositio e elocutio). Dessa forma, o procedimento adotado pela professora demonstra o enraizamento de práticas que legitimam a redação de vestibular, já que a definição das práticas escolares reflete o tipo de cobrança feita nos vestibulares de maneira geral. Há raras exceçôes nesse sentido.

Temos percebido, em conversas com professores da área (em oficinas oferecidas e / ou em projetos desenvolvidos em escolas públicas), que há ainda grandes dúvidas sobre como deve ser um trabalho de leitura e produção baseado em gêneros textuais. Muitos professores demonstram desconhecimento sobre a teoria e sobre orientaçôes a respeito, que constam, desde o final da década de 90, nos Parâmetros Curriculares Nacionais, por exemplo. Desse modo, predominam aulas de "redação", voltadas apenas para o vestibular e enfatizando as características estruturais do texto. $\mathrm{O}$ mais preocupante nesse processo é que a redação constitui-se no gênero da esfera escolar por excelência, totalmente desvinculada das práticas sociais de linguagem. Tais aspectos se refletem na sequência acima discutida, que propunha a produção de um texto com o tema dia das mães.

Ainda com relação a essa sequência de atividades, percebemos que o trabalho não envolveu atividades adequadas de planejamento (foram 
apresentados apenas alguns questionamentos para serem respondidos em forma de texto). Também não foram desenvolvidas atividades de leitura de outros textos com o mesmo tema, o que poderia ampliar o conhecimento de mundo dos alunos, além de tornar conhecidos outros "modelos" de textos, com a mesma sequência tipológica. Também poderiam ter sido trabalhados textos que possibilitassem o conhecimento da organização geral do próprio gênero que seria produzido (caso houvesse indicação desse gênero).

Outro aspecto importante nas atividades de produção de textos escritos é a reescritura do texto produzido, a partir da revisão individual ou colaborativa feita pelo próprio aluno. É uma fase importante do trabalho, no sentido de possibilitar ao aluno a monitoração de seu trabalho, tornando-o leitor de seu próprio texto. Tais revisões devem estar baseadas em parâmetros de avaliação fornecidos pelo professor ou pelo LD, quando for o caso.

Ao considerarmos a avaliação do trabalho com produção de textos apresentada pelo PNLD, via Guia do Livro Didático, percebemos que essas atividades são consideradas satisfatórias no LD “adotado" nesta escola e que é utilizado na maioria das práticas de linguagem da turma de $5^{\text {a }}$ série observada, pois envolvem a produção de inúmeros gêneros escolares, além de textos literários, publicitários, jornalísticos, científicos, entre outros. De acordo com a avaliação, o domínio da escrita é favorecido por atividades planejadas de modo coerente e detalhado, visando, principalmente, à observação dos traços característicos do gênero. Nesse sentido, o tratamento didático dispensado ao trabalho de produção, nesse LD, considera os usos socialmente contextualizados, além de instigar o aluno a refletir sobre determinado fato para, num segundo momento, fazer inferências objetivando a sistematização dos aspectos desenvolvidos.

Com base nessas questôes, percebemos que a produção de textos escritos, mediada pelo LD, poderia ser uma oportunidade de desenvolver atividades mais produtivas, visto que envolve orientaçóes voltadas para um trabalho com diferentes gêneros, o que se apresenta como altamente satisfatório. A atividade proposta em sala de aula, como referido, efetivamente se distancia de tais aspectos.

Em entrevistas realizadas com os alunos, percebemos que, fora da escola, a maioria deles costuma escrever algum texto (dos 24 alunos que participaram dos questionamentos, 17 dizem escrever alguma coisa fora da escola). Entre os gêneros preferidos estão, principalmente, a carta, o diário, a poesia, o desenho e a letra de música. É um dado importante a ser considerado, pois essa prática 
demonstra que o aluno escreve, que gosta de escrever (caso contrário só escreveria por obrigação) e que essas práticas envolvem diversos gêneros. $\mathrm{Na}$ escola, entretanto, praticamente não há espaço para isso. Seria uma boa oportunidade de aprimorar as habilidades que são iniciadas fora do contexto escolar, já que os textos produzidos poderiam servir de ponto de partida para o desenvolvimento de atividades em sala de aula, voltadas também para textos de real interesse dos alunos, além dos gêneros necessários para ampliar sua participação social. Por essa razão, nas práticas de produção escrita seria importante observar as situaçóes sociais que os alunos consideram significativas, além da interessante experiência prévia desses alunos com gêneros, ou ainda "tornar vital para o interesse dos alunos o terreno discursivo que queremos convidá-los a explorar” (BAZERMAN, 2006, p. 30).

Considerando ainda nesta discussão, as orientações disponíveis nos PCN, as atividades de produção de textos devem possibilitar ao aluno, entre outras coisas, que "utilize com propriedade e desenvoltura os padróes da escrita em função das exigências do gênero e das condiçōes de produção". Além disso, deve considerar os objetivos estabelecidos e o leitor a que se destina seu texto, ampliando, dessa forma, sua competência comunicativa (BRASIL, 1998, p. 52).

Tais observações nos direcionam para uma prática pedagógica ainda distante da realidade. Em observaçôes como as apresentadas neste trabalho, e também em outros projetos de produção textual desenvolvidos em escolas públicas, percebemos um distanciamento significativo entre as práticas de produção de textos realizadas e as orientações oficiais e acadêmicas. Embora saibamos das dificuldades enfrentadas pelos professores em seu dia a dia, com turmas numerosas, carga horária estafante, há que se pensar em uma alternativa que viabilize práticas mais produtivas de escrita, no sentido de habilitar o aluno a participar ativamente de sua sociedade.

Em algumas escolas, há aulas específicas destinadas apenas à produção textual. Pode ser uma alternativa interessante, embora saibamos que as práticas de leitura, produção e análise linguística estão intimamente ligadas. Porém, em função de ainda termos aulas de português que priorizam apenas conteúdos gramaticais, ter um espaço disponível para tentar orientar os alunos para uma escrita razoável pode ser um dos caminhos possíveis, principalmente se a questão dos gêneros discursivos perpassar essas práticas.

Outra tentativa de dinamizar o trabalho de leitura e produção de textos seria a organização de projetos voltados para esse fim. Experiências mostram resultados significativos nesse sentido, em função da resposta positiva e 
produtiva dos indivíduos que participam desse tipo de trabalho. Tais projetos envolveriam gêneros textuais de interesse dos alunos, no sentido de possibilitar a apropriação de habilidades de leitura e escrita que possam ser úteis em suas práticas sociais diárias. Só para citar um exemplo: uma proposta interessante para alunos de EJA, cujo principal objetivo é o mercado de trabalho, seria oportunizar o desenvolvimento de atividades de leitura e produção do gênero Curriculum vitae. Por apresentar características descritivas e informativas, ter um objetivo (concorrer a uma vaga de trabalho) e um interlocutor definidos (setor de recursos humanos de uma empresa), o trabalho com a linguagem seria extremamente produtivo. Certamente teríamos aí uma experiência positiva que auxiliaria esses alunos em seu dia a dia.

Outra possibilidade de desenvolver práticas produtivas de produção de textos está vinculada às propostas de alguns LDs. No livro utilizado pela professora nas aulas observadas, há, conforme indicações do PNLD, um trabalho adequado de produção de textos, visto que o planejamento das atividades favorece o desenvolvimento gradual do domínio da escrita, associando os gêneros utilizados na leitura e na produção. São organizadas atividades que levam o aluno a elaborar textos de diversos gêneros, observandose o planejamento, os traços característicos do gênero, a elaboração temática e a autoavaliação. Se bem conduzidos, tais procedimentos possibilitariam práticas de produção de textos voltadas para o desenvolvimento de diversas habilidades linguísticas e domínio gradativo de competências.

\section{Considerações finais}

Ao considerarmos que o ensino de língua portuguesa deve estar voltado para a função social da língua, a formação discursiva dos alunos ganha destaque em função das diversas práticas sociais em que eles poderão e / ou deverão interagir. Nesse sentido, percebemos que no sistema de atividades da escola há a inter-relação de diferentes sistemas de atividades, todos voltados, teoricamente, para esse fim.

Nesse contexto, o gênero LD se destaca como o principal mediador dessa esfera de atividades, servindo de ferramenta para o aluno e para o professor. Assim como se constitui uma ferramenta para o aluno atingir seus objetivos (principalmente a apropriação da variedade culta da língua), também cumpre papel semelhante se considerarmos o ponto de vista do professor, ou seja, serve como instrumento de controle das atividades linguísticas dos alunos. 
Sendo assim, nas atividades de linguagem em que está envolvido, o gênero LD se constitui como uma importante ferramenta, visto que permite a realização de diversas atividades sociais de linguagem. A atividade de produção de texto proposta na aula observada, como referido anteriormente, demonstra um descompasso entre as práticas do professor e as práticas pretendidas via LD. Mais que isso, demonstra a manutenção de práticas da tradição escolar e a falta de habilidade do professor em interagir com o LD, no sentido de selecionar criticamente as práticas de linguagem que julgar mais adequadas aos seus propósitos.

Ao considerarmos o contexto sócio-histórico dos diferentes agentes vinculados aos sistemas de atividades escolar, as regras explicitadas em cada comunidade da qual participam os agentes e a divisão de trabalho que se estabelece, percebemos que inúmeras tensóes podem se evidenciar nessa rede, o que poderia resultar numa reorganização e / ou mudança, em diferentes níveis dos sistemas. Analisando, por exemplo, o sistema de atividades do professor, as dificuldades por ele enfrentadas no dia a dia são visíveis. As tensões surgem da necessidade de atualização de conhecimentos, por meio de cursos de formação continuada, por exemplo; da necessidade de recuperação de orientações curriculares básicas, disponíveis há bastante tempo e que não foram suficientemente discutidas, o que se refletiria num diálogo aberto com os instrumentos mediadores do processo de ensino, especialmente o LD. Entretanto, percebemos que apesar das tensões surgidas nesse contexto ainda não vislumbramos as mudanças necessárias. Tais mudanças são discutidas e sugeridas, mas não atingem o alvo esperado, os agentes escolares. Por essa razão, o descompasso verificado entre professor, referenciais curriculares (políticas públicas educacionais) e a ferramenta LD permanece no cotidiano escolar.

Sendo assim, torna-se importante um olhar que se volte para as práticas estabelecidas na esfera escolar (entre agentes historicamente constituídos e socioculturalmente limitados e limitantes, mediadas por artefatos culturais), com o objetivo de possibilitar uma maior integração entre os membros de uma sociedade, diminuindo as diferenças e ampliando a possibilidade de participação social igualitária. 


\section{Referências}

BATISTA, A. A avaliação dos livros didáticos: para entender o Programa nacional do Livro Didático (PNLD). In: ROJO, R.; BATISTA. Livro didático de língua portuguesa, letramento e cultura da escrita. Campinas: Mercado de Letras, 2003. p. 25-67.

BAZERMAN, C. Gênero, agência e escrita. Trad. Judith Hoffnagel e Angela Paiva Dionísio. São Paulo: Cortez, 2006. 144 p.

BRASIL. Ministério da Educação e do Desporto. Parâmetros Curriculares Nacionais: terceiro e quarto ciclos do ensino fundamental: Lingua Portuguesa. Brasília, MEC/SEF, 1998. 107 p.

BRASIL. Ministério da Educação. Guia de livros didáticos PNLD 2008: Língua Portuguesa. Brasília: MEC, 2007. 150 p.

BUNZEN, C. Reapresentação de objetos de ensino em livros didáticos de língua portuguesa: um estudo exploratório. In: SIGNORINI, I. (Org.). Significados da inovaçāo no ensino de língua portuguesa e na formação de professores. Campinas: Mercado de Letras, 2007. 228 p.

KOCH, I.; FÁVERO, L. Contribuição a uma tipologia textual. Letras \& Letras, v. 3, n. 1, Uberlândia, 1987. p. 3 - 10.

MARCUSCHI, L. A. Gêneros textuais: definição e funcionalidade. In: DIONISIO, A.; MACHADO, A.; BEZERRA, M. A. (Org.). Gêneros textuais e ensino. 2. ed. Rio de Janeiro: Lucerna, 2003.

REINALDO, M. A. M. A orientação para produção de texto. In: DIONISIO, A.; BEZERRA. M. A. O livro didático de português: múltiplos olhares. Rio de Janeiro: Lucerna, 2005. p. 89-101.

ROJO, R. O perfil do livro didático de língua portuguesa para o ensino fundamental ( $5^{\mathrm{a}}$ a $8^{\mathrm{a}}$ séries). In: ROJO, R.; BATISTA, A. Livro didático de língua portuguesa, letramento e cultura da escrita. Campinas: Mercado de Letras, 2003. p. 69-99.

ROJO, R.; BATISTA, A. Livro didático de língua portuguesa, letramento e cultura da escrita. Campinas: Mercado de Letras, 2003.

Recebido em 14 de março de 2010. Aprovado em 8 de setembro de 2010. 